\title{
PROGNOSTIC IMPACT OF ISOCITRATE DEHYDROGENASE ENZYME ISOFORMS IDH1 \& IDH2 MUTATIONS IN ACUTE MYELOID LEUKEMIA
}

\author{
Sahar Samir Abd El Maksoud ${ }^{1}$, Rasha Abd El Rahman ElGamal ${ }^{1}$, Shaimaa \\ Abdelmalik Pessar ${ }^{1}$, Hanaa Fathey Abd El-Samee ${ }^{2}$, Dalia Ahmed Diaa El-Dine \\ Salem $^{1}$, and Heba Samy Agamy ${ }^{1}$
}

${ }^{1}$ Clinical Pathology, ${ }^{2}$ Internal Medicine Department, Faculty of Medicine, Ain Shams

University

Corresponding :

Heba Samy Agamy

Mobile: 01006865078

E mail:

d.hebasamy@yahoo.com

Received: $12 / 8 / 2019$

Accepted: 10/9/2019

\section{ABSTRACT:}

Background: IDH1 \& 2 mutations are one of the most common genomic abnormalities which have recently been described in acute myeloid leukemia (AML) patients. Mutant IDH1/2 enzymes have neomorphic activity and catalyze the reduction of ketoglutarate to an oncometabolite, which promotes DNA and histone hypermethylation, altered gene expression, and impaired hematopoietic differentiation.

Aim of the work: To evaluate the prognostic impact of both IDH1 and IDH2 mutations in newly diagnosed AML patients and their correlation with different clinical and laboratory parameters.

Patients and Methods: The present study was conducted on 56 de novo adult AML patients who attended Haematology/Oncology unit of Ain-Shams University Hospitals during the period from July 2017 till July 2018. They were assessed for the presence of IDH 1\& 2 SNP mutations using Real-Time PCR Patients with MDS, biphenotypic leukemia and associated malignancy were excluded from our study.

Results: Heterozygous mutations of IDH1 SNP rs11554137\& IDH2R140Q SNP were detected in a percentage of $14.3 \%$ and $16.1 \%$ respectively. Upon assessing the clinical outcome at day 28, mutant IDH2R140Q SNP group showed significant unfavourable outcome $(p=0.045)$. While at 6 months, all patients with IDH1 SNP rs11554137mutation died and seven out of nine patients with mutant IDH2R140Q died,so IDH1 SNP rs11554137 showed significant unfavourable outcome at 6 months $(p=0.016)$. The survivors showed significantly younger age, lower mean platelets and blast counts, as well as negative IDH1 SNP rs11554137 ( $p=0.014,0.046,0.009$ and 0.016 respectively)Multivariate logistic regression analysis identified high BM blasts percentage as an independent prognostic predictor for 6 month mortality ( $p=0.014$, OR 1.049, 95\% CI 1.010 to 1.090).

Conclusion: IDH1 SNP rs11554137 in CN-AML is associated with unfavourable clinical outcome and worse DFS at 6months,and was univariate factor in non survivors patients. while IDH2R140Q was associated with unfavourable clinical outcome at day28 after induction.Including IDH1\&IDH2 mutations in AML routine gene panel, will be valuable for prognostication.

Keywords: Isocitrate Dehydrogenase Enzyme, IDH1 \& IDH2, Acute Myeloid Leukemia, Real Time PCR. 


\section{INTRODUCTION:}

Acute myeloid leukemia (AML) is a clonal malignant disease of hematopoietic tissue caused by somatic mutations in genes that control normal cell proliferation and differentiation ${ }^{[1]}$.

The molecular genetic alterations are one of the most important prognostic factors that have been identified in AML and the role of these genetic alterations has been emphasized by the 2008 revised World Health Organization classification of AML like nucleophosmin (NPM) 1, and CCAAT enhancer-binding protein $\alpha$ (CEBPA), Wilms-tumor (WT1), Fms-like tyrosine kinase3 (FLT3) ${ }^{[2]}$.

Identification of new gene mutations provides useful markers for diagnosis, prognosis assessment and making therapeutic decision with monitoring therapy ${ }^{[3]}$. Among these are epigenetic mutations that include isocitrate dehydrogenase mutations; IDH1 and IDH $2^{[4]}$.

IDH proteins are homodimeric enzymes involved in diverse cellular processes, including adaptation to hypoxia, histone demethylation and DNA modification ${ }^{[4]}$.

The IDH2 protein is localized in the mitochondria and is a critical component of the tricarboxylic acid (also called the 'citric acid' or Krebs) cycle. Both IDH2 and IDH1 (localized in the cytoplasm) proteins catalyze the oxidative decarboxylation of isocitrate to $\alpha$-ketoglutarate $(\alpha-K G)^{[5]}$.

The mutations confer neomorphic enzyme activity through the NADPHdependent reduction of the normal endproduct $\alpha$-ketoglutarate to the putative oncometabolite 2-hydroxyglutarate. The accumulation of high levels of 2hydroxyglutarate in the IDH1/2-mutant tumor provides an important mechanism of cellular transformation through the targeting of epigenetic regulators ${ }^{[6]}$.
The IDH1 and IDH2 mutations have been identified in glioma, cartilaginous tumors, thyroid carcinomas, cholangiocarcinoma, prostate cancers, paragangliomas, melanoma, chronic-, fibrotic-, or blastphases of essential thrombocythemia, polycythemia vera or myelofibrosis, and AML. In AML, the IDH1 and IDH2 mutations are frequently associated with blastic transformation or aggressive forms ${ }^{[7]}$.

Several methods, including PCR and sequencing, are commonly used for IDH detection $^{[8]}$. Because IDH mutations occur in approximately one in five patients with AML, mutational testing should be part of routine molecular assessment at diagnosis to identify patients who may in time benefit fromtargeted treatmentscurrently under clinical study ${ }^{[9]}$. Identification of these mutations at diagnosis may also be pivotal for better risk stratification of AML patients $^{[10]}$.

\section{AIM OF THE WORK:}

To evaluate the prognostic impact of both IDH1 and IDH2 mutations in newly diagnosed AML patients and their correlation with different clinical and laboratory parameters.

\section{SUBJECTS AND METHODS:}

I. Study Subjects: The present cohort study was conducted on 56 de novo adult AML patients who attended Haematology/Oncology unit of AinShams University Hospitals during the period from July 2017 till July 2018.

The diagnosis and classification of acute leukemia were based on the WHO 2016 Classification of Tumors of Haematopoeitic and Lympoid Tissues.

Patients with MDS, biphenotypic leukemia and associated malignancy were excluded from our study. 
All patients were subjected to treatment regimen in Haematology /Oncology unit of Ain-Shams University Hospitals as followed:

\section{Induction therapy: $3+7$ protocol:}

Begin with Adriamycin $25 \mathrm{mg} / \mathrm{m} 2$ IV/15 min. infusion for 3days then shift to Cytarabine $100 \mathrm{mg} / \mathrm{m} 2 / 12 \mathrm{hr}$ for 7 days.

After achieving complete remission (CR) After induction, patients were given three courses of postremission therapy (consolidation) with high dose ara-C Cytarabine $3 \mathrm{~g} / \mathrm{m} 2$ every $12 \mathrm{~h}$ by continuous IV infusion over $3 \mathrm{~h}$ on days 1, 3 and 5 . The three consolidation courses were administered at monthly intervals.

Patients were evaluated by clinical examination, $\mathrm{PB}$ and $\mathrm{BM}$ aspirate after induction and consolidation therapy and followed up to 6months (for the living patients) to assess the prognostic impact of IDH1\&2 mutations on disease outcome.

Informed consent either verbal or written was obtained from all enrolled patients, all the study protocols were in approval of the Scientificand Ethical Committee of Ain-Shams University, and the number of the patient included in the study was recommended by medical statistical center Ain-Shams University.

\section{All patients were subjected to the following:}

A. Full history taking.

B. Through clinical examination, laying stress on the presence of extramedullary disease (hepatomegaly, splenomegaly, and lymphadenopathy).

C. Laboratory investigations including:

1. Complete blood picture using $\mathrm{LH}$ 750 cell counter (Coulter, Electronics, Hialeah, FL, USA) with examination of Leishman's stained PB smears.

2. BM aspiration with examination of Leishman's stained BM smears(BM aspiration at diagnosis, day 28 after induction therapy and at 6months)

3. Cytochemical studies using Myeloperoxidase (MPO) stain.

4. Immunophenotyping (IPT) on BM aspirate/PB samples by whole blood lysis performed on Coulter Navios flow cytometer (Coulter, Electronics, Hialeah, FL, USA)., using the standard panel for acute leukemia using a panel of monoclonal antibodies (either fluorescein isothiocyanate (FITC) or phycoerythrin (PE) - labeled).

5. Cytogenetic analysis using fluorescence in situ hybridization technique (FISH). The results of conventional karyotyping were obtained from patients' files

\section{Methods:}

Detection of IDH1 \& IDH2 mutations by (real time PCR): all samples were analysed for the detection of IDH1 \&2 mutations expression levels by Real-Time PCR (Custom TaqMan SNP Genotyping, SNP IDrs11554137 A105G for IDH1 and SNP IDrs121913502 Q140R for IDH2 ).

After DNA extraction that was performed using Genomic DNA Extraction kit, according to manufacturer's spin protocol (Gene Proof manufactured).

\section{Statistical analysis:}

Data were analyzed using NCSSC 12 Statistical Software 2018 (NCSS, LLC. Kaysville, Utah, USA) and XLSTAT(C) version 19.5 (Addinsoft $($, Paris, France).

Continuous numerical data were presented as mean and standard deviation and intergroup differences were compared using the unpaired $t$ test.

Categorical data were presented as ratio or number and percentage and intergroup differences were compared using Fisher's exact test. Ordinal data were compared using the chi-squared test for trend. 
The predictive value of IDH genotype was examined using 2-by-2 contingency of the binary outcome (e.g., death/survival) versus the genotype (heterozygous/normal)

Two-sided p-values $<0.05$ were considered statistically significant.

\section{RESULTS}

IDH1 SNP rs 11554137 were detected in $8(14.3 \%)$, By comparing patients with normal or heterozygous IDH1SNP there is significantly higher platelet count, blast count and age in patients with heterozygous mutant IDH1SNP than those with wild type. After 6months follow up all patients with IDH1SNP mutation have unfavorable 6 months clinical outcome and disease free survival (DFS) both have the same positive significance (0.016) which illustrated in table1

Table (1): Comparison between normal and mutant IDH1 rs11554137 patients

\begin{tabular}{|c|c|c|c|c|}
\hline & & $\begin{array}{c}\text { Normal } \\
\text { IDH1 rs11554137 } \\
(\mathrm{N}=48,85.7 \%)\end{array}$ & $\begin{array}{c}\text { Heterozygous } \\
\text { IDH1 rs11554137 } \\
(\mathrm{N}=8,14.3 \%)\end{array}$ & p-value*\# \\
\hline Age (years) & Mean \pm SD & $42.1 \pm 14.2$ & $62.3 \pm 15.7$ & 0.001 \\
\hline $\begin{array}{l}\text { Gender } \\
\text { Male } \\
\text { Female }\end{array}$ & N (\%) & $\begin{array}{l}35(72.9) \\
13(27.1)\end{array}$ & $\begin{array}{l}4(50) \\
4(50)\end{array}$ & 0.228 \\
\hline Hemoglobin $(\mathrm{g} / \mathrm{dl})$ & Mean \pm SD & $6.7 \pm 1.7$ & $7.3 \pm 1.0$ & 0.355 \\
\hline $\operatorname{TLC}\left(\times 10^{9} / \mathrm{L}\right)$ & Mean \pm SD & $68.4 \pm 39$ & $72.7 \pm 58.7$ & 0.788 \\
\hline Platelets $\left(\times 10^{9} / \mathrm{L}\right)$ & Mean \pm SD & $26.6 \pm 16.2$ & $48.1 \pm 9.2$ & 0.001 \\
\hline Blast cells (\%) & Mean \pm SD & $69.6 \pm 16.1$ & $87.8 \pm 6.3$ & 0.003 \\
\hline $\begin{array}{l}\text { IDH2R140Q } \\
\text { Normal } \\
\text { Heterozygous }\end{array}$ & $\mathrm{N}(\%)$ & $\begin{array}{c}40(83.3) \\
8(16.7) \\
\end{array}$ & $\begin{array}{l}7(87.5) \\
1(12.5) \\
\end{array}$ & 1.000 \\
\hline $\begin{array}{l}\text { Outcome at } 28 \text { days } \\
\text { Favorable }^{+} \\
\text {Unfavorable }^{++}\end{array}$ & N (\%) & $\begin{array}{l}17(35.4) \\
31(64.6)\end{array}$ & $\begin{array}{c}0(0) \\
8(100)\end{array}$ & 0.090 \\
\hline $\begin{array}{l}\text { Outcome at } 6 \text { months } \\
\text { Favorable }^{+} \\
\text {Unfavorable }^{+++}\end{array}$ & N (\%) & $\begin{array}{l}23(47.9) \\
25(52.1)\end{array}$ & $\begin{array}{c}0(0) \\
8(100)\end{array}$ & 0.016 \\
\hline
\end{tabular}

N: Number; SD: Standard Deviation; TLC: Total Leucocytic Count; IQR: Interquartile range.

* Unpaired t test for quantitative data with parametric distribution

\# Chi-square testfor qualitative data

Fisher's exact testwhen the expected count in any cell was found less than 5

+ Favorable outcome $=\mathrm{CR}$ (Complete remission)

++ Unfavorable outcome $=\mathrm{D}($ Dead $)$ or PR $($ Partial remission $)$

+++ Unfavorable outcome $=$ D $($ Dead $)$ or R $($ Relapse)IDH2R140Q were detected in $9(16.1 \%)$.

By comparing patients with normal or heterozygous IDH2R140Q there is significantly higher platelet counts, older age and lower TLC in patients with heterozygous mutant IDH2R140Q than those with wild type. There is significant difference between clinical outcome at day 28and IDH2 R140Q mutations (patients with mutant IDH2R140Q have unfavorable outcome at day28 after induction than patients with wild type which illustrated in table 2 
Table (2): Comparison between normal and mutant IDH2 R140Q patients:

\begin{tabular}{|c|c|c|c|c|}
\hline & & $\begin{array}{l}\text { Normal IDH2R140Q } \\
\quad(\mathrm{N}=47,83.9 \%)\end{array}$ & $\begin{array}{c}\text { Heterozygous IDH2R140Q } \\
\text { Mutation } \\
(\mathrm{N}=9,16.1 \%)\end{array}$ & p-value*\# \\
\hline Age (years) & Mean \pm SD & $42.6 \pm 16.0$ & $57.2 \pm 8.5$ & 0.011 \\
\hline $\begin{array}{l}\text { Gender } \\
\text { Male } \\
\text { Female }\end{array}$ & $\mathrm{N}(\%)$ & $\begin{array}{l}33(70.2) \\
14(29.8)\end{array}$ & $\begin{array}{l}6(66.7) \\
3(33.3)\end{array}$ & 1.000 \\
\hline Hemoglobin $(\mathrm{g} / \mathrm{dl})$ & Mean \pm SD & $6.7 \pm 1.5$ & $7.3 \pm 2.2$ & 0.332 \\
\hline $\mathrm{TLC}\left(\mathrm{x} 10^{9} / \mathrm{L}\right)$ & Mean \pm SD & $77.9 .4 \pm 39.1$ & $22.2 \pm 15.6$ & $<0.001$ \\
\hline Platelets $\left(\times 10^{9} / \mathrm{L}\right)$ & Mean \pm SD & $25.9 \pm 13.2$ & $49.1 \pm 22.7$ & $<0.001$ \\
\hline Blast cells (\%) & Mean \pm SD & $70.4 \pm 17.0$ & $81.3 \pm 7.4$ & 0.066 \\
\hline $\begin{array}{l}\text { IDH1SNPrs11554137 } \\
\text { Normal } \\
\text { Heterozygous }\end{array}$ & $\mathrm{N}(\%)$ & $\begin{array}{c}40(83.3) \\
7(14.9) \\
\end{array}$ & $\begin{array}{l}8(88.9) \\
1(11.1) \\
\end{array}$ & 1.000 \\
\hline $\begin{array}{l}\text { Outcome at } 28 \text { days } \\
\text { Favorable }^{+} \\
\text {Unfavorable }^{++}\end{array}$ & $\mathrm{N}(\%)$ & $\begin{array}{l}17(36.2) \\
30(63.8) \\
\end{array}$ & $\begin{array}{c}0(0) \\
9(100) \\
\end{array}$ & 0.045 \\
\hline $\begin{array}{l}\text { Outcome at } 6 \text { months } \\
\text { Favorable }^{+} \\
\text {Unfavorable }^{+++}\end{array}$ & $\mathrm{N}(\%)$ & $\begin{array}{l}21(44.7) \\
26(55.3)\end{array}$ & $\begin{array}{l}2(22.2) \\
7(77.8)\end{array}$ & 0.282 \\
\hline
\end{tabular}

N: Number; SD: Standard Deviation; TLC: Total Leucocytic Count; IQR: Interquartile range.

* Unpaired t test for quantitative data with parametric distribution

\# Chi-square test for qualitative data

Fisher's exact test when the expected count in any cell was found less than 5

+ Favorable outcome $=\mathrm{CR}$ (Complete remission)

++ Unfavorable outcome $=\mathrm{D}($ Dead $)$ or PR $($ Partial remission $)$

+++ Unfavorable outcome $=\mathrm{D}($ Dead $)$ or R $($ Relapsed $)$

By comparing 6-months survivors and non survivors regarding available data.

We found that only 4 variables had an effect on the survivors patients (IDH1 rs11554137mutation, age of the patient, blast cell count and platelet count).

Table (3): Comparison between survivors and non-survivors at 6 months)

\begin{tabular}{|c|c|c|c|c|}
\hline & & $\begin{array}{c}\text { Survivors } \\
(\mathrm{N}=23,41.1 \%)\end{array}$ & $\begin{array}{c}\text { Died } \\
(\mathrm{N}=33,58.9 \%)\end{array}$ & p-value*\# \\
\hline Age (years) & mean \pm SD & $38.8 \pm 10.7$ & $49.2 \pm 17.7$ & 0.014 \\
\hline $\begin{array}{l}\text { Gender } \\
\text { Male } \\
\text { Female }\end{array}$ & $\mathrm{N}(\%)$ & $\begin{array}{c}18(46.2) \\
5(29.4)\end{array}$ & $\begin{array}{l}21(53.8) \\
12(70.6)\end{array}$ & 0.376 \\
\hline Hemoglobin $(\mathrm{g} / \mathrm{dl})$ & Mean \pm SD & $6.3 \pm 1.5$ & $7.1 \pm 1.6$ & 0.067 \\
\hline TLC $\left(\times 10^{9} / \mathrm{L}\right)$ & Mean \pm SD & $72.4 . \pm 34.5$ & $66.6 \pm 46.5$ & 0.616 \\
\hline Platelets $\left(\times 10^{9} / \mathrm{L}\right)$ & Mean \pm SD & $24.2 \pm 9.5$ & $33.5 \pm 20.1$ & 0.046 \\
\hline Blast cells (\%) & Mean \pm SD & $65.4 \pm 17.8$ & $76.9 \pm 13.6$ & 0.009 \\
\hline $\begin{array}{l}\text { IDH1 rs11554137 } \\
\text { Normal } \\
\text { Heterozygous }\end{array}$ & $\mathrm{N}(\%)$ & $\begin{array}{c}23(47.9) \\
0(0)\end{array}$ & $\begin{array}{c}25(52.1) \\
8(100)\end{array}$ & 0.016 \\
\hline $\begin{array}{l}\text { IDH2 R140Q } \\
\text { Normal } \\
\text { Heterozygous }\end{array}$ & N (\%) & $\begin{array}{c}21(44.7) \\
2(22.2)\end{array}$ & $\begin{array}{c}26(55.3) \\
7(77.8)\end{array}$ & 0.282 \\
\hline
\end{tabular}

N: Number; SD: Standard Deviation; TLC: Total Leucocytic Count; IQR: Interquartile range.

* Unpaired $\mathrm{t}$ test for quantitative data with parametric distribution

\# Chi-square testfor qualitative data

Fisher's exact testwhen the expected count in any cell was found less than 5 
In multi variate analysis for the 3 numerical parameters affected 6 months mortality we found that both age, platlet have poor predictive value (AUC $=0.68$, 0.61 respectively) while blast cells has fair predictive value $(\mathrm{AUC}=0.7)$ as illustrated in table 4

Furthermore By using stepwise regression analysis age, blast cell count, platelet count and IDH1 rs11554137 were included but only blast cells count was retained while other variates were removed.The blast cell count was the only independent predictive variate (AUC $=0.702,95 \% \quad \mathrm{CI}=0.564$ to 0.817$)$. as illustrated in table 5

Table (4): Receiver-operating characteristic (ROC) curve analysis for prediction of 6-month mortality

\begin{tabular}{|l|c|c|c|}
\hline \multicolumn{1}{|c|}{ ROC curve parameter } & Age & Platelets & Blast cells \\
\hline Area under the ROC curve (AUC) & 0.688 & 0.615 & 0.702 \\
\hline Standard Error & 0.071 & 0.075 & 0.072 \\
\hline 95\% Confidence interval & 0.551 to 0.805 & 0.475 to 0.742 & 0.564 to 0.817 \\
\hline z statistic & 2.660 & 1.539 & 2.790 \\
\hline Significance level P (Area=0.5) & 0.008 & 0.124 & 0.005 \\
\hline Youden index J & 0.455 & 0.320 & 0.340 \\
\hline Associated criterion & $>58$ & $>37$ & $>64$ \\
\hline Sensitivity, \% & 45.5 & 36.4 & 81.82 \\
\hline Specificity, \% & 100 & 95.7 & 52.17 \\
\hline
\end{tabular}

Table (5): An alternative logistic regression model for prediction of 6-month mortality using stepwise regression

\begin{tabular}{|c|c|c|c|c|c|c|}
\hline Variable & Coefficient & SE & Wald & P-value & Odds ratio & $95 \% \mathrm{CI}$ \\
\hline Blast cells $\left(\mathrm{k} / \mathrm{mm}^{3}\right)$ & 0.048 & 0.019 & 6.006 & 0.014 & 1.049 & 1.010 to 1.090 \\
\hline Constant & -3.051 & 1.418 & 4.633 & 0.031 & & \\
\hline \multicolumn{7}{|c|}{ Variables removed by stepwise regression } \\
\hline \multicolumn{7}{|c|}{ Age, Platelets count, IDH1 rs11554137 } \\
\hline \multicolumn{7}{|c|}{ Overall model fit } \\
\hline \multicolumn{3}{|c|}{2 Log Likelihood } & \multicolumn{4}{|c|}{$\mathrm{P}$-value $=0.008$} \\
\hline \multicolumn{3}{|c|}{ Nagelkerke pseudo- $\mathrm{R}^{2}$} & \multicolumn{4}{|c|}{0.159} \\
\hline \multicolumn{3}{|c|}{ Hosmer \&Lemeshow } & \multicolumn{4}{|c|}{$\mathrm{P}$-value $=0.943$} \\
\hline \multicolumn{3}{|c|}{ Area under the ROC curve (AUC) } & & \multicolumn{3}{|c|}{$0.702(\mathrm{SE}=0.072,95 \% \mathrm{CI}=0.564$ to 0.817$)$} \\
\hline
\end{tabular}

$\mathrm{R}=$ regression coefficient, $\mathrm{SE}=$ standard error, $95 \% \mathrm{CI}=95 \%$ confidence interval.

\section{DISCUSSION}

Acute myeloid leukemia is a heterogeneous hematological malignancy characterized by the clonal expansion of myeloid blasts in the peripheral blood, bone marrow and/or other tissues ${ }^{[11]}$. Although advances in supportive care and prognostic risk stratification have optimized established therapies, overall long-term survival remains poor $^{[12]}$.

The diagnosis of AML mainly depends on the features of morphology, immunology, cytogenetics and molecular biology. IDH mutations are one of the most common genomic abnormalities in AML.IDH mutations in AML may define specific disease subtypes with discrete genomic context and clinical and prognostic implications ${ }^{[13]}$.

The prognostic impact of IDH $1 / 2$ mutations in AML is highly variable. It is likely that these differences are at least partially due to differences in patient populations, study methodology, grouping of mutations for prognostic analysis, and 
influence of additional genomic abnormalities $^{[14]}$

With the advent of prognostic heterogeneity in IDH gene aberrations in acute myeloid leukemia patients, it is necessary to determine what prognostic differences are between various subtypes of IDH aberrations, especially in cases with intermediate-risk karyotype (normal karyotype) who were harboring higher frequency of IDH mutations ${ }^{[15]}$

Accordingly, the aim of this study was to evaluate the prognostic impact of both IDH1 and IDH2 mutations in newly diagnosed AML patients and their correlation with different clinical and laboratory parameters.

Fifty six newly diagnosed AML patients were evaluated for expression of mutant IDH1\&2 using real time PCR.

Heterozygous IDH1 SNP rs11554137 \& IDH2R140Q SNP mutations were detected in $8(14.3 \%)$ and $9(16.1 \%)$ patients respectively. None of them presented with homozygous mutations. Only one patient had both IDH isoforms mutations.

The frequency of IDH1 rs11554137 (8 out of $56 ; 14.3 \%$ ) is considered comparable to that reported in similar study conducted on Egyptian AML patients Ali et al., where IDH1 rs11554137 mutated cases (using sequencing method) was $6(11.8 \%)$ out of 51 CN AML patients ${ }^{[16]}$

In addition to $\mathrm{HO}$ et al., who detect IDH1 rs11554137 mutation in $30(11 \%)$ out of 274 patients of overall American adult AML cases, and Wagner et al. who also found that $31 / 275 \quad(12 \%)$ have IDH1 rs11554137 mutation among all German adult CN AML cases in the study ${ }^{[17,18]}$

However regarding IDH2R140Q mutation, our study showed $9(16 \%)$ were positive for gene mutation which is higher than that found in the study conducted on Egyptian AML adult patients by Aref et al. who found IDH2R140Q mutation in $20(9.4 \%)$ out of 211 AML cases. This difference may be attributed to different number of studied population. Another study by Willander et al. has reported IDH2R140Q mutation in 21(11.1\%) out of 189 adult AML cases ${ }^{[9,19]}$

In the current study, we found that IDH2R140Q is relatively more common than IDH1 rs11554137 (16 vs14.2\%). This is in concordance with Willander et al. who revealed that IDH2 mutations were more common than IDH1 mutations $(13.8 \%$ vs $7.9 \%$ respectively). ${ }^{[19]}$

Which mean that there was no significant association seen for concomitant mutation of IDH1 and IDH2 genes which suggests that these mutations are mutually exclusive. This come in agreement with Saadi et al. who revealed no significant association between IDH1 and IDH2 mutations and similar to Aref et al. stated that no mutated cases had both IDH1 and IDH2 mutations. ${ }^{[20,9]}$

In our study, on comparing IDH1 rs 11554137 positive and negative patient groups, we found that the IDH1 rs11554137 mutation was highly significantly detected in the following patients groups: older age group $(p=0.011)$, those with higher blast count $(p=0.004)$ and those with high platelet counts $(p=0.001)$. Conversely there was no significant difference as regard its frequency in both sexes $(p=0.228)$, hemoglobin and TLC show normal values in both wild and mutant type.

However, Ho et al. revealed no association between the studied IDH1 polymorphism and age $(\mathrm{P}=0.59)$, blast number or platelet count. The only significant difference was between racial groups $(\mathrm{P}=0.0046)$, mostly because of a high proportion of blacks $(30 \%)$ among SNP-positive patients more than white and Asian race. Moreover they stated that IDH1 rs11554137 was not found in adult patients 
with $t(8,21)$ or $\operatorname{inv}(16) / t(16,16)$ which was similar to our results. ${ }^{[17]}$

In our study, on comparing IDH2R140Q mutation positive and negative patients, we found that IDH2 mutation was highly significantly detected in patients with older age $(p=0.011)$, low WBC count $(p<0.001)$ and high platelet counts $(\mathrm{p}<0.001)$ and with no significant difference as regard $\operatorname{sex}(\mathrm{p}=1)$, hemoglobin concentration $(\mathrm{p}=0.332)$ and BM blast cell counts $(\mathrm{p}=0.058)$.

Similarly a comparison conducted by Aref et al. found that IDH2 mutation was significantly higher in patients with older age $(p=0.05)$, and low WBC count $(p=0.02)$ and high platelet counts $(\mathrm{p}=0.01)$ and with no significant difference as regard sex, extra medullary infiltration, hemoglobin concentration and BM blast cell counts. Also studies conducted by Chotirat et al. and Paschka et al. found that IDH2 mutation was associated with older age and a higher platelet count but they found that the IDH2 mutation was not associated with low WBC counts. ${ }^{[9,21,1]}$

Similarly, Willander et al. found only IDH2 mutant-positive patients were significantly older than IDH2-wild type $(\mathrm{P}=0.001)$ but there was no difference according to sex, French-American-British subtype and WBC count ${ }^{[19]}$

In our study we revealed the bad prognostic outcome of patients who carry mutant IDH1 rs11554137 in relation to complete remission and DFS $(\mathrm{P}=0.016)$. Also we found that only 4 variables had an effect on the OS of the patients which are presence of IDH1 rs11554137, age of the patient, blast cell count and platelet count. So IDH1 rs11554137 mutant patients has inferior OS in univariate study, however in multivariate study there was no impact on OS. While the blast cell count was the only variable which showed fair significance $(\mathrm{AUC}=0.72)$.
Similarly $\mathrm{Ho}$ et al. stated that SNP positivity in adult AML patients was a significant risk factor for decreased RFS in univariate analysis ${ }^{[17]}$

In line with our results Ali et al. found that the presence of IDH1 rs11554137 was significantly associated with inferior DFS ( $P$ $=0.037)$ and $\mathrm{OS}(\mathrm{P}=0.034)$ as compared with wild-type. Several lines of evidence suggested that the IDH1 rs11554137 was associated with poor prognosis in terms of both DFS and OS ${ }^{[16]}$

Similarly Wagner et al. found that the IDH1 rs11554137 was an independent predictor of inferior OS, and also correlated with inferior RFS in cytogenetically normal adult AML using a univariate model. However in contrast to our results the presence of IDH1 rs11554137 was an independent prognostic factor for the patients with $\mathrm{CN}$-AML using multivariate analysis. ${ }^{[18]}$

In our study there is significant correlation between clinical outcome at day 28 and IDH2 R140Q mutations (patients with mutant IDH2R140Q have unfavorable outcome at day28 after induction than patients with wild type) $(\mathrm{p}=0.045)$. These results comes in clear contradiction to results of Aref et al. who revealed that there was no significant association between IDH2 mutation on neither the induction nor remission rate $(\mathrm{P}=0.4)$. [9]

Similar to our results, the study conducted by Willander et al. has found significantly shorter OS for the IDH2 codon 140 mutations in comparison to patients with wild type $(\mathrm{HR}=1.94 ; 1.07-3.53 ; 95 \%$ confidence interval, $\mathrm{p}=0.03$ ).Contrarily, Patel et al. have found a favorable outcome for patients with mutant IDH2 codon 140 . $[19,22]$

In the study of Patel et al. the patients' median age at diagnosis was much lower than in our study, 48 vs. 61 years respectively. This may indicate that the 
effect of the IDH2 mutation is more evident in elderly patients. The study of Willander et al. validate the concept of the association between IDH2R140Q and the shorter OS while the median age of the study group was 64 years; this is similar to median age value of our patients(61 years). ${ }^{[22,19]}$

Similarly, meta analysis done by $\mathrm{Xu}$ et al. found that the IDH2 (R140) mutation was associated with prolonged OS among younger patients (mean/median age $<50$ years, $\mathrm{HR}=0.64 ; 95 \% \mathrm{CI}, 0.49-0.82, \mathrm{P}=$ 0.906)when compared with older patients (mean/median age $>50$ years, HR, 1.11; 95\% CI, 0.37-3.33, P = 0.010), and he concluded that the IDH2(R140) mutation in younger cases was notably related to better OS, reflecting that older age might be a more powerful factor in contributing to poor prognosis than the IDH2 (R140) mutation does. ${ }^{[15]}$

However, $\mathrm{Xu}$ et al. added that among CN-AML patients, mutant IDH2 had no impact on OS $(\mathrm{P}=0.2114)$ and that the discrepancy of survival between CN-AML and cytogenetically abnormal karyotype belonging to intermediate risk, such as isolated trisomy $8, \mathrm{t}(9 ; 11)$ and some non defined karyotypes. ${ }^{[15]}$

In contrast to our results, Green et al. revealed that IDH2R140Q patients had a favorable response to therapy and improved OS ( $p=0.008)$, But not a significant factor in multivariable analysis for complete remission. ${ }^{[23]}$

They refered this favorable response of IDH2R140Q mutation to presence of concomitant NPM1MUT, so it can clarify the discrepancy between the both results.

However NPM mutation was not assessed in our study so comparison with this study not applicable.

\section{Conclusion:}

In conclusion, IDH1/2 SNPs mutations are non random events in CN-AML with confirmed adverse prognostic impact on patients' outcome. IDH1 SNP rs11554137 \& IDH2R140Q mutations diversely affect prognosis of CN-AML patients based on the location of the mutation. Mutant IDH2R140Q SNP group is associated with unfavorable clinical outcome on day 28 of chemotherapy, while both mutations are associated with poor outcome and short disease free survival at 6 months. Including both IDH1\&IDH2 mutations in AML routine gene panel will be valuable for prognostication and assignment of therapeutic protocol. Molecular 'fingerprinting' of AML for IDH 1/2 mutations may help to guide the use of both conventional and novel agents in this disease

\section{REFERENCES:}

1. Paschka P, Schlenk R, Gaidzik V, Habdank M, Krönke J, Bullinger L, Späth D, Kayser S, Zucknick M, Götze K and Horst H. IDH1 and IDH2 mutations are frequent genetic alterations in acute myeloid leukemia and confer adverse prognosis in cytogenetically normal acute myeloid leukemia with NPM1 mutation without FLT3 internal tandem duplication. J. Clin. Oncol 2010; 28: 36363643.

2. Sjöblom T, Jones S, Wood L, et al. The consensus coding sequences of human breast and colorectal cancers. Science 2006;314:268-74.

3. Scholl S, Fricke H, Sayer H, Hoffken K. Clinical implications of molecular genetic aberrations in acute myeloid leukemia. J Cancer Res Clin Oncol 2009; 135(4):491505.

4. Clark O, Yen $\mathrm{K}$ and Mellinghoff $\mathrm{I}$, et al. Molecular Pathways: Isocitrate Dehydrogenase Mutations In Cancer. Clin Cancer Res2016; 22: 1-7.

5. Molenaar RJ, Thota S, Nagata Y, Patel B, Clemente M, Hirsh $\mathrm{C}$ et al. Clinical and biological implications of ancestral and non-ancestral IDH1 and IDH2 mutations in myeloid neoplasms. Leukemia 2015; 29 : 2134-2142. 
6. Platt MY, Fathi AT, Borger DR, Brunner AM, Hasserjian RP, Balaj L et al. Detection of dual IDH1 and IDH2 mutations by targeted next-generation sequencing in acute myeloid leukemia and myelodysplastic syndromes. J Mol Diagn 2015; 17: 661-668.

7. Nomdedéu J, Hoyos M, Carricondo M, et al. Adverse impact of IDH1 and IDH2 mutations in primary AML: experience of the Spanish CETLAM group. Leuk Res 2012; 36:990-7.

8. Mahdieh N and Rabbani B. An overview of mutation detection methods in genetic disorders. Iran J Pediatr 2013; 23: 375-388.

9. Aref S, Kamel Areida el S, Abdel Aaal MF, Adam OM, El-Ghonemy MS, El-Baiomy MA et al. Prevalence and clinical effect of IDH1 and IDH2 mutations among cytogenetically normal acute myeloid leukemia patients. Clin Lymphoma Myeloma Leuk 2015; 15: 550-555.

10. Jin J, Hu C, Yu M, Chen F, Ye L, Yin X et al. Prognostic value of isocitrate dehydrogenase mutations in myelodysplastic syndromes: a retrospective cohort study and meta-analysis. PLoS One 2014; 9: e100206.

11. O'Donnell MR, Abboud CN, Altman J, et al. NCCN Clinical Practice Guidelines Acute myeloid leukemia. J Natl ComprCancNetw. 2012; 10(8):984-1021.

12. De Kouchkovsky I and Abdul-Hay M. Acute myeloid leukemia: a comprehensive review and 2016 update. Blood Cancer Journal 2016; 6(7):e441.

13. Avellaneda D, Grunseth AJ, Gonzalez ER et al. Molecular mechanisms of isocitrate dehydrogenase 1 (IDH1) mutations identified in tumors: the role of size and hydrophobicity at residue 132 on catalytic efficiency. J. Biol. Chem. 2017; 292(19): 7971-7983.

14. Boddu P, Borthakur G. Therapeutic targeting of isocitrate dehydrogenase mutant AML, 2017; 525-530.
15. Xu Q, Li Y, Lv N, Jing Y, Xu Y, Li Y, Li W, Yao Z, Chen X, Huang S, Wang L. Correlation between isocitrate dehydrogenase gene aberrations and prognosis of patients with acute myeloid leukemia: a systematic review and metaanalysis. Clinical Cancer Research. 2017; 23(15):4511-22.

16. Ali YB, Mohamed AF, Ebid GT, Guirgis AA. A New Method to Detect IDH1 Synonymous SNP 105 C> T rs 11554137. Current Applied Science and Technology. 2018; 18(3):192-9.

17. Ho PA, Kopecky KJ, Alonzo TA, Gerbing RB, Miller KL, Kuhn J et al. Prognostic implications of the IDH1 synonymous SNP rs 11554137 in pediatric and adult AML: a report from the Children's Oncology Group and SWOG. Blood 2011; 118:4561-4566.

18. Wagner K, Damm F, Göhring G, Görlich K, Heuser M, Schäfer I, Ottmann O, Lübbert M, Heit W, Kanz L, Schlimok G. Impact of IDH1 R132 mutations and an IDH1 single nucleotide polymorphism in cytogenetically normal acute myeloid leukemia: SNP rs 11554137 is an adverse prognostic factor. Journal of Clinical Oncology. 2010; 28(14):2356-64.

19. Willander K, Falk IJ, Chaireti R, Paul E, Hermansson M, Green $\mathrm{H}$, et al. Mutations in the isocitrate dehydrogenase 2 gene and IDH1 SNP $105 \mathrm{C}>\mathrm{T}$ have a prognostic value in acute myeloid leukemia. Biomarker Res 2014; 2:18.

20. Saadi MI, Zarei T, Ramzi M, Arandi N. Mutation of the DNMT3A and IDH1/2 genes in Iranian acute myeloid leukemia patients with normal karyotype (CN-AML): association with other gene mutation and clinical and laboratory characteristics. Journal of Hemato-pathology. 2018; 11(2):29-36.

21. Chotirat S, Thongnoppakhun W, Wanachiwanawin W, Auewarakul CU. Acquired somatic mutations of isocitrate dehydrogenases 1 and 2 (IDH1 and IDH2) in preleukemic disorders. Blood Cells, Molecules, and Diseases. 2015; 54 (3): 28691. 
22. Patel JP, Gonen M, Figueroa ME et al. Prognostic relevance of integrated genetic profiling in acute myeloid leukemia. New England Journal of Medicine 2012; 366: 1079-89.
23. Green ClaireL., Catherine M. Evans, The prognostic significance of IDH2 mutations in AML depends on the location of the mutation 2018; 18: 